Conference Proceedings

Journal of Technology in Counselor Education and Supervision (ISSN 2692-4192)

Volume 1(1): 45 - 48

(C) 2021Journal of Technology in Counselor Education and Supervision

https://doi.org/10.22371/tces/008

\title{
Counselor Education Online Curriculum Design: Social Justice Considerations
}

\author{
Lisa McKenna' \& Amie A. Manis²
}

\begin{abstract}
COVID-19 accelerated the adoption of distance learning in 2020 throughout the world. Online education is now central to counselor education and the trend will likely continue post COVID-19 as well. The history of distance education technology in counselor education is first explored and then the advantages and challenges of this learning model are discussed along with the ethical, legal and regulatory implications. Finally, the future of counselor education is explored along with emerging technologies that may again disrupt our teaching and learning models.
\end{abstract}

Keywords

online counselor education, backward design, competency-based education, systematic assessment, infusing social justice

The use of technology has gained considerable momentum in counselor education as more programs are being offered in full and partial online platforms (ACES Technology Interest Network, 2017; Snow \& Coker, $2020)$. With the global pandemic beginning in 2020 , many programs that had not yet offered online courses were challenged to quickly shift to an online format. This change provides an opportunity to carefully reflect on best practices in online course design and assessment at the student, class, and program level.

When given the responsibility of designing a course for any mode of delivery, faculty may struggle with where to begin. There may be an inclination to find a good primary resource such as a reliable text, and then work from there developing lectures, study aids, and assignments. An alternative approach is to begin by thinking about the course learning outcomes, and what competencies students will need to develop and demonstrate once working in the field. Once the course outcomes are identified, an assessment plan including the formative and summative learning activities is the next design step. In order to promote deep learning and consistent student developmental progress, the instructional design must be well-conceptualized with each component intentionally built in to support

$1 \quad$ Liberty University, Lynchburg, VA, USA

2 University of Alaska Fairbanks, Fairbanks, AK, USA the end result (Czersawski, 2014; Wiggins \& McTighe, 2005).

We aim to provide a brief illustration of the application of two models to support effective course design for online delivery of the counselor education curriculum. The first, which we have found especially wellsuited for counselor education, is competency-based education. Designing with competencies that align to the Council for Accreditation of Counseling and Related Educational Programs (CACREP) standards in the forefront, is also consonant with the second model, the backward design. This approach recognizes the importance of formative and summative assessments that are responsive to diverse learning styles and authentic to the field of practice (Alalshaikh, 2015; Moates \& Cox, 2015). Further, the use of technology for full or partial delivery of a course or program curriculum presents the advantage of an embedded assessment strategy to support real-time generation of student learning outcomes (SLOs) data. This promotes opportunities for intervention at the student, course and program level (Akos, 2019). An example of how the approach can be applied to measuring competency development as a social justice advocate is offered.

Corresponding Author: Lisa McKenna, PhD, Liberty University, 1971 University Blvd., Lynchburg, VA 24515 email: Imckenna2@liberty.edu 


\section{Competency-based Education Model}

Competency-based education is an intentional and transparent approach to curricular design that communicates to students the competencies needed in order to be successful in their careers following graduation (Competency-Based Education Network, 2017). Articulating competencies in a clear manner provides a road map for programs to develop a well-conceptualized curriculum. It also allows students the ability to understand what will be expected of them post-graduation in the field, and how what they are learning in their programs supports their development. According to Soares (2012), competency-based education is an outcomes-oriented model where the emphasis is on what students can do in terms of skills and abilities. As such, ongoing assessment is instrumental in determining student progression, and movement forward is based on demonstrated success at each level. In a competency-based education model, students demonstrate their knowledge and skills by engaging in learning exercises, activities, and experiences that align with clearly defined programmatic outcomes, often termed student learning outcomes (SLOs). The assessments involved in competency-based education include both formative assessments and summative assessments. With formative assessments in particular, students receive proactive guidance and support from faculty with the intention of giving them the personalized feedback needed to continue development toward mastery. Examples of formative assessments may include quizzes, discussions, papers, presentations, etc. The feedback provided by faculty through formative assignments is generally given more emphasis than the score, as the goal is to support development of competencies leading up to a summative assessment (the measurement of knowledge and/or skill expected at the conclusion of the course) (Competency-Based Education Network, 2017).

Leuse (2015) highlighted several ways technology can support a competency-based design and assessment process. For example, software programs can be used to track the relationships between course learning objectives and program level SLO's. Additionally, quantitative scores as well as qualitative feedback offered by faculty on assessments can also be tracked within and across courses. With competency-based education, the combination of a well-conceptualized course intentionally focused on student development of the competencies required in the professional field coupled with the technology to support the design and assessment process provide a structure for an effective and empowering curriculum for the program.

\section{Backward Design Approach}

The backward design approach, broadly speaking, involves three main steps (Wiggins \& McTighe, 2005). First, aligned with the competency-based education model, faculty curriculum designers first consider what competencies they want to see students develop in the course, and ensure that these competencies are aligned to internal and external outcomes. Second, an assessment plan is developed that addresses type of assessment, timing of assessment, and alignment of scoring criteria to course learning objectives and industry standards. Third, the class content and activities are built to scaffold the learning experience and provide the students with opportunities to develop the competency.

Figure 1. Backward Design

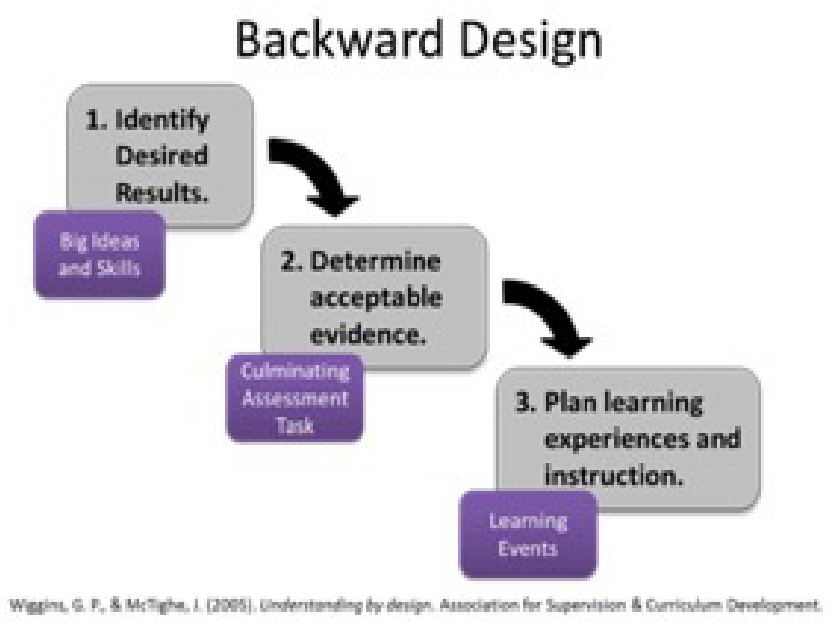

The backward design approach fits well with programs that follow accreditation requirements to assess student progress. For example, CACREP (2016) standard 4.F states (boldface added here for emphasis):

The counselor education program faculty systematically assesses each student's progress throughout the program by examining student learning in relation to a combination of knowledge and skills. The assessment process includes the following: (1) identification of key performance indicators of student learning in each of the eight core areas and in each student's respective specialty area(s) (for doctoral programs, each of the five doctoral core areas), (2) measurement of student learning conducted via multiple measures and over multiple points in time, and (3) review or analysis of data. (pp. 18-19)

With the backward design approach, the program identifies the key performance indicators (KPIs) that reflect the external standards required by the professional field. These KPIs are aligned to SLO, and the 
faculty designer intentionally aligns the SLO to specific learning objectives for the course). The faculty designer then develops assessments to measure performance on the KPIs. It is a known fact that individuals have unique learning styles, and as such faculty need to be sensitive to include a variety of assessment strategies within a course (Alalshaikh, 2015; Moate \& Cox, 2015). This can also support a quality course by offering different learning experiences which encourages engagement and effectively meets the needs of diverse and non-traditional students (Czerkawski, 2014; Dixon-Saxon \& Buckley, 2020). Drilling down deeper, the faculty designer also considers the specific scoring criteria and how they align to course learning objectives, as well as the student performance level. At both the course level and the program level, offering multiple opportunities for students to demonstrate performance on specific KPIs provides an opportunity for deeper learning for the student as well as the ability to track level of development over time.

\section{Assessment of Results}

Reviewing assessment data is essential for multiple reasons. At a student-level, reviewing progress highlights opportunities for intervention to better support progress and development. This can occur when faculty review results of an individual assessment or multiple assessments that measure performance on the same KPI across the course and/or program. At a program level, faculty and administrators can identify from a review of the data if there are opportunities for further data-driven course and/or program refinement and modifications. While the plan may appear different across various institutions, the common theme is that there is a plan that answers the question 'did the design achieve the goals?' A high level process with the intent to provide a structure for the continuous assessment cycle of student progress and performance that can be a helpful guide for faculty may be 1) Review results, 2) Initiate recommendations, and 3) Implement recommendations.

Figure 2. Assessing Student Progress

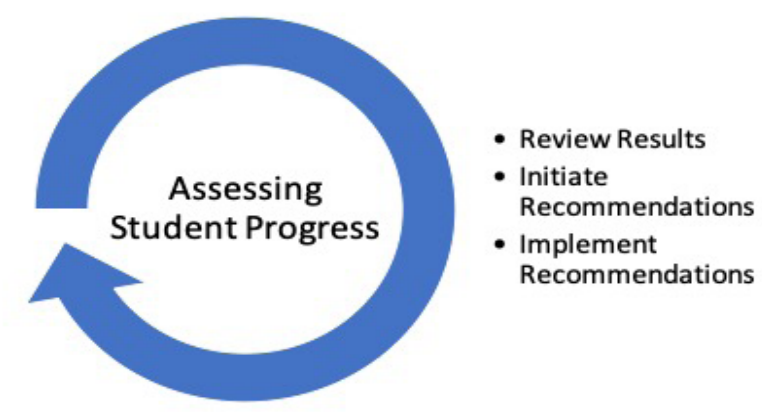

Data is only useful if it is regularly reviewed and analyzed, and this often happens at multiple levels (faculty, staff, administrators, etc.). Questions to ask in this process may include "Did the assessment measure the KPI as intended?" "Are there opportunities for refinement in the assessment instructions? The scoring critera? The course content and activities that support understanding and mastery?" "Is there redundancy vs scaffolding in this assessment from prior assessments in course/program?" If the outcomes data indicate the possibility for opportunities to enhance student learning within the course design, faculty are well positioned to put forward data-informed recommendations for improvement. Once the modifications are implemented, the cycle continues with a careful review of the data and analysis to determine if the changes had a positive impact.

\section{Example Application of Social Justice Competency}

Infusing culturally alert and responsive practice and skills, such as social justice advocacy, is central to counselor education (Decker et al. 2016). This example applies the curriculum development models when a SLO for a course is based on CACREP Standards (2016) aimed at guiding the preparation and assessment of trainees as social justice advocates. Aligned with a backward design approach, the first step of course design begins with understanding the requirements of the profession, and articulating how graduates of the counseling program will be able to demonstrate they have achieved a particular student learning outcome (SLO). Faculty may determine following a review of CACREP standards to put forward a SLO such as: To demonstrate multicultural awareness and engage in social justice and advocacy efforts to support the well-being of individuals affected by oppression. For example, within the context of the particular course the faculty designer may expect the student to be able to identify advocacy needs and opportunities for a client population in their community. With this goal in mind, the faculty designer will then consider a developmental approach to assessment including both formative and summative assessments that will be able to measure the students' progress in mastery. Decker et al. (2016) suggested a number of activities that promote social justice competency development which may also serve as assessments. For example, faculty may develop a case study assignment in which students identify diverse client needs and opportunities to advocate at the micro, meso and macro levels. This offers the potential to encourage deeper learning. It also yields assessment data on students' mastery and application of the concepts required to be successful beyond 
the course in real-life situations. Additionally, a variety of assessments is not only engaging students, it also reflects appreciation of differing student strengths and learning styles (ACES Technology Interest Network, 2017). Other examples that support infusion of social justice advocacy across the curriculum may include drafting a letter on a public policy to a legislator, journaling or developing a reflection paper on a designated volunteer or service learning project, or researching and presenting on a social justice issue in their community (Decker et al., 2016). Faculty may also consider performance level when assigning weight to the assignment, such as having earlier assignments with lower weight/risk and building to more weight as expectation of progression increases.

Once the assessments are in place, the next step will be for the faculty designer to determine learning activities that will foster success. This can include choosing relevant reading assignments such as textbooks and articles, watching videos, and engaging in interactive activities such as peer discussions and practice sessions or networking with professionals in the community. Leveraging the diverse backgrounds that students bring to the classroom setting by building peer interaction and meaningful dialogue into the learning activities provides an enriching learning experience (Czerkawski, 2014). Pan et al. (2012) provided evidence for the benefit of instructors creating videos in online courses that support deeper learning and engagement.

\section{Conclusion}

Once the course has been designed, we have found it is helpful to have additional review of the course for feedback. This is another benefit to the role of technology in curriculum design, as the written version of the course can often be shared easily where other faculty and administrators can review and provide feedback internally. The course can also made accessible for evaluation against industry standards for counselor education and online curriculum (e.g., CACREP and/ or Quality Matters). After the course has been delivered, the cycle of continuous assessment continues as data is closely monitored on course performance and data-driven recommendations are put forward to support further refinement.

\section{References}

ACES Technology Interest Network. (2017). Guidelines for distance education. https://www.nbcc.org/Assets/COVID/ACESGuidelinesforOnlineLearninginCounselorEducation.pdf

Council for Accreditation of Counseling and Related Educational Programs. (2015). 2016 CACREP standards. http://
www.cacrep.org/wp-content/uploads/2017/08/2016-Standards-with-citations.pdf

Akos, P., Wasik, S.Z., McDonald, A., Soler, M., \& Lys, D. (2018). The challenge of competency-based counselor education. Counselor Education \& Supervision, 58, 98111. $10.1002 /$ ceas. 12134

Alalshaikh, S. (2015). Cultural impacts on distance learning, online learning styles, and design. The Quarterly Review of Distance Education, 16(3), 67-75.

Competency-Based Education Network. (2017). Quality framework for competency-based education programs. https://www.cbenetwork.org/wp-content/ uploads/2018/09/1st_button_CBE17016_Quality_ Framework_Update.pdf

Czerkawski, B.C. (2014). Designing deeper learning experiences for online instruction. Journal of Interactive Online Learning, 13(2), 29-40.

Decker, K.M., Manis, A.A. Paylo, M.J. (2016). Infusing social justice advocacy into counselor education: Strategies and recommendations. The Journal of Counselor Preparation and Supervision, 8(3), Retrieved from https://repository.wcsu.edu/jcps/vol8/iss3/1/

Dixon-Saxon, S., \& Buckley, M.R. (2020). Student selection, development, and retention: A commentary on supporting success in distance counselor education. The Professional Counselor, 10(1),57-77. 10.15241/sds.10.1.57

Leuse, M. (2015). Competency-based education: Technology challenges and opportunities. Educause Review. https://er.educause.edu/articles/2015/10/competencybased-education-technology-challenges-and-opportunities

Moate, R.M., \& Cox, J.A. (2015). Learner-centered pedagogy: Considerations for application in a didactic course. The Professional Counselor, 5(3), 379-389. 10.15241/ rmm.5.3.379

Pan, G., Sen, S., Starrett, D. A., Bonk, C. J., Rodgers, M. L., Tikoo, M., \& Powell, D. V. (2012). Instructor- made videos as a scaffolding tool. Journal of Online Learning and Teaching, 8(4), 298.

Snow, W.H \& Coker, K. (2020). Distance counselor education: Past, present, future. The Professional Counselor, 10(1),40-56. 10.15241/whs.10.1.40

Soares, L. (2012). A disruptive look at competency-based education. Center for American Progress. https://cdn.americanprogress.org/wpcontent/uploads/issues/2012/06/pdf/ comp_based_education.pdf

Wiggins, G., \& McTighe, J. (2005). Understanding by design. Alexandria, VA: Association for Supervision and Curriculum Development. 